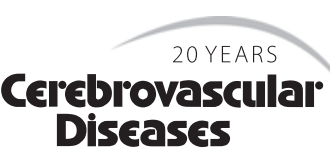

Diseases

\title{
Prevention of Stroke in Patients with Atrial Fibrillation: The Role of New Antiarrhythmic and Antithrombotic Drugs
}

\author{
Joachim Röther ${ }^{\mathrm{a}, \mathrm{b}}$ Harry Crijns ${ }^{c}$ \\ a Johannes Wesling Klinikum Minden, Hannover Medical School, Minden, and ' ${ }^{\mathrm{b}}$ Department of Neurology,

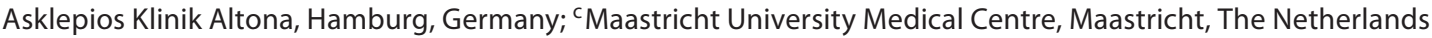

\section{Key Words}

Atrial fibrillation • Ischemic stroke • Antiarrhythmic drug • Anticoagulation

\begin{abstract}
Background: Atrial fibrillation (AF) is the most common sustained cardiac arrhythmia. It is associated with increased cardiovascular mortality and morbidity, including stroke. $\boldsymbol{R e}$ sults: Rate or rhythm control and prevention of thromboembolism with oral anticoagulants are the main management objectives for patients with AF. Until recently, rhythm control studies did not show prevention of cardiovascular complications. However, dronedarone, a novel antiarrhythmic drug, has been shown to decrease stroke risk by $34 \%(p=0.027)$. In addition, the Randomized Evaluation of Long-Term Anticoagulant Therapy trial showed significant stroke reductions with the anticoagulant dabigatran $150 \mathrm{mg}$ b.i.d. compared with adjusted-dose warfarin (the results for dabigatran 110 mg b.i.d. were similar to warfarin). Conclusions: Novel antithrombotic agents and antiarrhythmic agents with cardiovascular prophylactic properties may enhance the management of stroke risk in patients with AF.
\end{abstract}

Copyright $\odot 2010$ S. Karger AG, Base

\section{KARGER}

Fax +41613061234 E-Mail karger@karger.ch www.karger.com
(C) 2010 S. Karger AG, Basel

$1015-9770 / 10 / 0303-0314 \$ 26.00 / 0$

Accessible online at:

www.karger.com/ced

\section{Impact of Atrial Fibrillation}

Atrial fibrillation (AF) is the most common sustained cardiac arrhythmia, affecting approximately $1 \%$ of adults [1]. The prevalence of AF in the population increases dramatically with age, with AF occurring in $9 \%$ of those aged 80 years and older. In the USA alone, the prevalence of AF is projected to triple by 2050 [2].

Long-term studies have consistently associated AF with increased cardiovascular morbidity and mortality [3-5]. In the Framingham Heart Study, patients with AF had nearly a 5 -fold increased risk of stroke compared with individuals without AF [6]. Data from that study demonstrated that the attributable risk of stroke for patients with AF increases progressively with age, ranging from $1.5 \%$ in individuals aged $50-59$ years to $23.5 \%$ in those aged 80-89 years [6]. In the Modified Framingham Stroke Risk Profile, AF was shown to be an independent predictor of stroke for sex-specific, 10-year cumulative risk of stroke [7]. The Copenhagen City Heart Study found that AF increased the risk of stroke in women by 10 -fold and doubled risk in men [8]. Moreover, that study showed an independent effect of AF on cardiovascular mortality, with a risk 2.5 times greater in women than in men [9]. Furthermore, in the Northern Manhat-

E-Mail j.roether@asklepios.com 
$\tan$ Stroke Study, AF was an independent risk factor for ischemic stroke along with hypertension, diabetes, coronary artery disease, physical inactivity and heavy alcohol use [10].

Guidelines jointly published by the American College of Cardiology, American Heart Association (AHA) and European Society of Cardiology classify recurrent $\mathrm{AF}$ as paroxysmal (self-terminating), persistent (nonself-terminating, usually lasting $>7$ days) and permanent (cardioversion has failed or is deemed inappropriate) [1]. The observational Euro Heart Survey on AF provided evidence that stroke risk with paroxysmal AF is 'at least comparable' to persistent or permanent $\mathrm{AF}$ [11]. Patients with permanent AF at baseline in the study had a higher stroke risk than patients with either persistent or paroxysmal AF, but actual ischemic stroke events at 1-year follow up were similar for all 3 patient groups (paroxysmal, 1.9\%; persistent, 1.2\%; permanent, $1.6 \%$; $\mathrm{p}=0.592)$. The survey showed a trend for higher prevalence of AF on electrocardiogram (ECG) at baseline in patients with paroxysmal AF who subsequently suffered stroke than in those who did not. However, at present there are no robust data demonstrating an association between AF burden (duration and frequency of AF) and stroke apart from an analysis by Capucci et al. [12] suggesting that AF lasting $>24 \mathrm{~h}$ is associated with a higher stroke risk.

\section{AF- and Stroke-Related Morbidity}

Stroke in patients with AF is severer and is nearly twice as likely to be fatal compared with non-AF stroke [13]. This difference may be attributed to the development of larger thrombi in the left atrial appendage, which is relatively wide compared with other sites in the arterial circulation. Obviously, larger emboli may occlude proximal or territorial arteries of the brain [14]. The occlusion of larger arteries results in larger infarct volumes and consequently severer neurologic deficits and worse outcomes.

A population-based study in Italy showed that the annual mortality rate in patients with a first-ever ischemic stroke and AF was twice that of patients without AF [15]. AF has also been shown to be an independent historical predictor of myocardial infarction (MI) or vascular death after first ischemic stroke [16]. Moreover, patients with $\mathrm{AF}$ are at an increased risk of stroke recurrence after the first ischemic stroke $[13,17]$.

Prevention of Stroke in Patients with Atrial Fibrillation

\section{Diagnosis of AF}

Because of these compelling associations of AF with increased stroke risk, early diagnosis of all forms of arrhythmia using ECG seems crucial to stroke prevention. To enhance stroke prevention, ECG screening for asymptomatic AF in high-risk populations may be important, but the clinical value and feasibility needs to be evaluated in randomized trials [18]. Diagnosis of AF can be confirmed by bedside telemetry or an ambulatory Holter monitor [1]. However, AF is frequently undetected by short-term ECG monitoring, in instances such as their use in stroke units, and the sensitivity of a single 24-hour Holter ECG for AF detection is limited. Therefore, more effective diagnostic tools such as event recorders need to be established [19]. The likelihood of AF is especially high in patients with cryptogenic stroke, and extended ECG telemetry is likely to identify patients with heretofore undetected AF [20].

The management of this aspect of stroke risk is complicated by asymptomatic AF, which often goes undetected. In a study of patients with artificial pacemakers, Israel et al. [21] demonstrated a high incidence of AF recurrence $>48 \mathrm{~h}$ duration in asymptomatic patients. The complications and risks of such silent episodes of AF are believed to be similar to those associated with symptoms [22].

\section{Management and Treatment}

In current guidelines, rate or rhythm control strategies and prevention of thromboembolism are the main management objectives for patients with AF [1]. Restoration of sinus rhythm aims to abolish symptoms of AF and reduce the cardiovascular and thromboembolic complications of this disorder. However, large trials have not shown a benefit of rhythm control over rate control strategies in this respect, which suggests that sinus rhythm is a marker of AF control rather than the instrumental cause of stroke-free survival.

Primary prevention of stroke in patients with AF is highly efficient and reduces the risk by $68 \%$ (relative risk reduction) compared with placebo [23]. Decisions regarding anticoagulation therapy are based on risk stratification [24]. For patients with AF, the $\mathrm{CHADS}_{2}$ [Cardiac failure, Hypertension, Age, Diabetes, Stroke (doubled)] scoring system provides a clear framework for assessing stroke risk [25]. It incorporates elements of several stratification schemes and assigns 1 point each for congestive

Cerebrovasc Dis 2010;30:314-322 
Table 1. Mortality, thromboemboli and stroke in randomized AF trials

\begin{tabular}{|c|c|c|c|c|c|c|c|c|c|}
\hline \multirow[t]{2}{*}{ Trial } & \multirow[t]{2}{*}{$\mathrm{n}$} & \multirow[t]{2}{*}{$\begin{array}{l}\text { Follow-up } \\
\text { years }\end{array}$} & \multirow[t]{2}{*}{$\begin{array}{l}\text { Age } \\
\text { years }\end{array}$} & \multicolumn{2}{|c|}{$\begin{array}{l}\text { Mortality } \\
\%\end{array}$} & \multicolumn{2}{|c|}{$\begin{array}{l}\text { Thromboembolic } \\
\text { complication, } \%\end{array}$} & \multicolumn{2}{|c|}{$\begin{array}{l}\text { Stroke or } \\
\text { TIA, \% }\end{array}$} \\
\hline & & & & $\begin{array}{l}\text { rhythm } \\
\text { control }\end{array}$ & $\begin{array}{l}\text { rate } \\
\text { control }\end{array}$ & $\begin{array}{l}\text { rhythm } \\
\text { control }\end{array}$ & $\begin{array}{l}\text { rate } \\
\text { control }\end{array}$ & $\begin{array}{l}\text { rhythm } \\
\text { control }\end{array}$ & $\begin{array}{l}\text { rate con- } \\
\text { trol }\end{array}$ \\
\hline AF-CHF [37] & 1,376 & 3.1 & 67 & 32 & 33 & NR & NR & 3 & 4 \\
\hline AFFIRM [38] & 4,060 & 3.5 & 69.7 & 23.8 & 21.3 & NR & NR & 7.1 & 5.5 \\
\hline HOT-CAFE [39] & 205 & 1.7 & 60.8 & 2.9 & 1.0 & NR & NR & 2.9 & 0 \\
\hline RACE [40] & 522 & 2.3 & 68 & 6.8 & 7.0 & 7.9 & 5.5 & NR & NR \\
\hline STAF [41] & 200 & 1.6 & 65 & 4 & 8 & 5 & 2 & 5 & 1 \\
\hline
\end{tabular}

$\mathrm{NR}=$ Not reported; AF-CHF = Atrial Fibrillation and Congestive Heart Failure; AFFIRM = Atrial Fibrillation Follow-Up Investigation of Rhythm Management; HOT-CAFE = How to Treat Chronic Atrial Fibrillation; RACE = Rate Control versus Electrical Cardioversion for Persistent Atrial Fibrillation; STAF = Strategies of Treatment of Atrial Fibrillation.

heart failure, hypertension, age $\geq 75$ years and diabetes, and 2 points for a history of stroke or transient ischemic attack (TIA). The AHA/American Stroke Association (ASA) Council on Stroke evidence-based guidelines address the primary prevention of stroke in patients with AF [26].

For patients with ischemic stroke or TIA and AF, i.e. $\mathrm{CHADS}_{2} \geq 2$, adjusted-dose warfarin [target international normalized ratio (INR), 2.0-3.0] is recommended $[24,27]$. Patients unable to take oral anticoagulants (OACs) should use aspirin $325 \mathrm{mg} /$ day. The AHA/ASA guidelines recommend the initiation of OACs within 2 weeks of an ischemic stroke or TIA in patients with AF [27]. The UK National Institute for Health and Clinical Excellence (NICE) recommends that patients with disabling ischemic stroke who are in AF should be treated with aspirin $300 \mathrm{mg}$ for the first 2 weeks before consideration of anticoagulation treatment [28]. The rationale for delaying OAC initiation is the potential for increased risk of early bleeding in patients with disabling strokes and large infarct volumes $[29,30]$.

In patients with $\mathrm{AF}$, guideline-conformant use of OACs prior to stroke decreases the severity of recurrent or first-ever ischemic stroke. In a retrospective review of records for 13,559 patients with AF, Hylek et al. [31] found that therapeutic anticoagulation to INR $>2.0$ reduced the frequency, severity and mortality of ischemic strokes. The benefits of preadmission warfarin were confirmed in an observational study of 948 patients admitted to hospitals in Ontario, Canada, with ischemic stroke and AF [32]. Data from the study showed that warfarin with a therapeutic INR level ( $>2$ ) on admission reduced the initial stroke severity and reduced disability at discharge or death compared with nontherapeutic warfarin, aspirin or no antithrombotic treatment.

Whereas the WASPO (Warfarin vs. Aspirin for Stroke Prevention in Octogenarians) and BAFTA (Birmingham Atrial Fibrillation Treatment of the Aged) trials showed that warfarin was safe and effective in older individuals, the risk for bleeding does increase with age $[33,34]$. Additionally, uncontrolled hypertension, history of MI or ischemic heart disease, cerebrovascular disease, anemia or a history of bleeding and the concomitant use of other drugs such as antiplatelet agents are associated with bleeding [35]. Bleeding risk stratification schemas have been proposed, such as the HEMORR ${ }_{2}$ HAGES score for AF patients [36], but additional validation of their value is needed.

\section{AF Therapy and Stroke Reduction}

A review of 5 randomized clinical trials in patients with AF (table 1) [37-41] showed that stroke and systemic emboli occurred more frequently in patients treated with a rhythm control strategy compared with a rate control strategy [42]. The author suggested that the difference may be related to discontinuation of warfarin treatment in patients thought to be converted to sinus rhythm. This finding highlights the need for the maintenance of long-term anticoagulation therapy in high-risk AF patients even if rhythm control is considered successful.

Stroke end points have not been regularly reported in clinical trials of antiarrhythmic drugs, and until recently 
Fig. 1. Cumulative risk in the ATHENA study of a stroke and $\mathbf{b}$ the composite outcome of stroke, acute coronary syndrome or cardiovascular death [46]. Reprinted with the permission of Circulation.
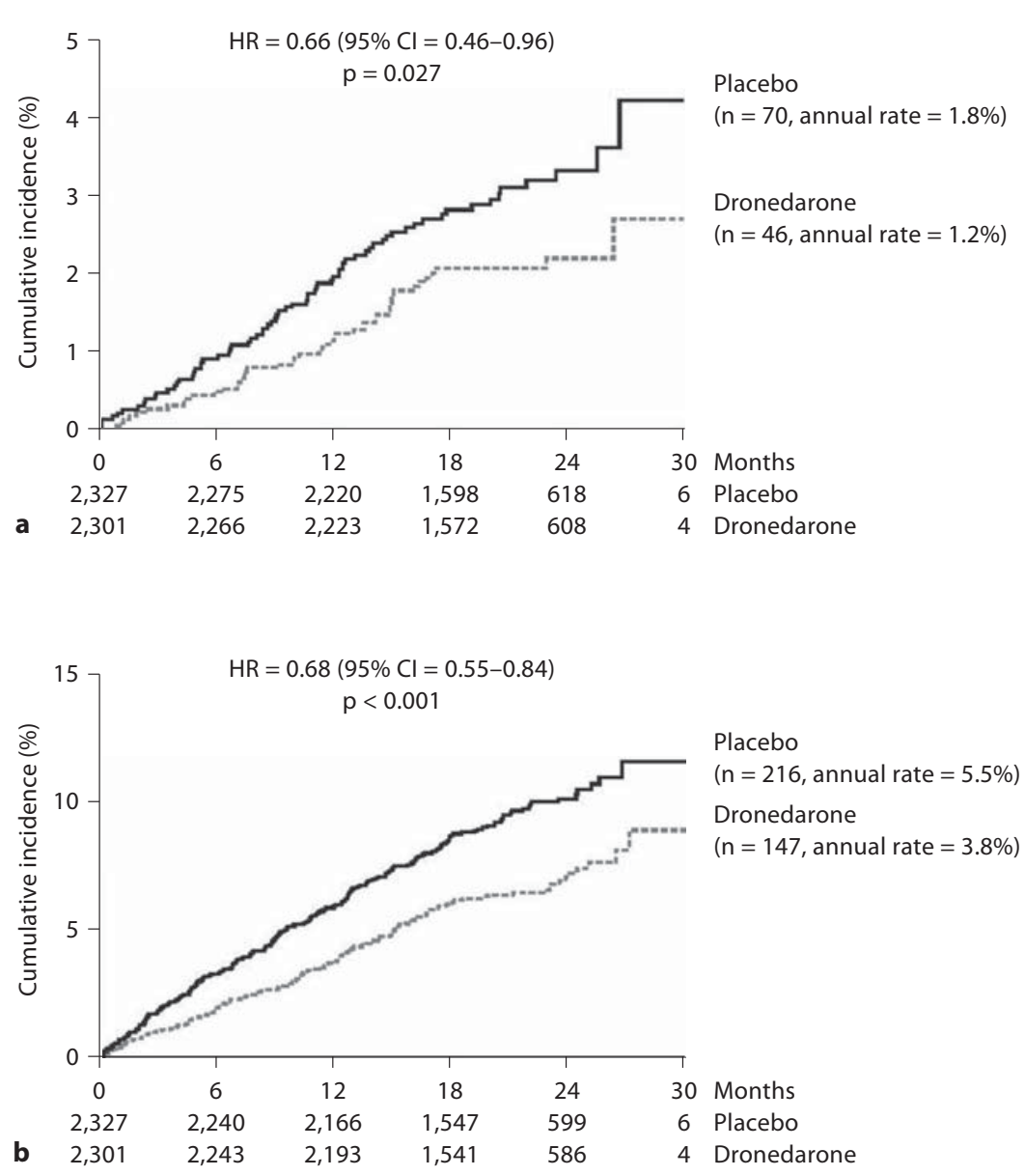

Dronedarone no AF treatment apart from OAC has been conclusively shown to reduce stroke incidence [43]. The SAFE-T (Sotalol Amiodarone Atrial Fibrillation Efficacy Trial), which reported minor and major stroke rates, showed no significant differences in those end points for patients $(\mathrm{n}=655)$ treated with amiodarone, sotalol or placebo [44].

Dronedarone, a novel antiarrhythmic drug, has been shown to reduce the risk for first cardiovascular hospitalization or death by $24 \%$ [ $95 \%$ confidence interval (CI) $=$ $0.69-0.84 ; \mathrm{p}<0.001]$ in patients with AF and additional risk factors for death [45]. ATHENA (a Placebo-Controlled, Double-Blind, Parallel Arm Trial to Assess the Efficacy of Dronedarone $400 \mathrm{mg}$ for the Prevention of Cardiovascular Hospitalization or Death from any Cause in Patients with Atrial Fibrillation/Atrial Flutter) randomized 4,628 patients to placebo or dronedarone 400 $\mathrm{mg}$ b.i.d. in addition to background OACs or antiplatelet drugs [45]. Patients with either paroxysmal or persistent AF or atrial flutter were eligible for the study, and $>10 \%$ of the patients had suffered either a TIA or a stroke before inclusion. The ATHENA trial did not include patients with permanent AF.

A post hoc analysis of the ATHENA data showed that dronedarone decreased the risk of stroke (ischemic or hemorrhagic) compared with placebo by 34\% [46 (1.2\% per year) vs. 70 (1.8\% per year) stroke events, respectively; hazard ratio $(\mathrm{HR})=0.66(95 \% \mathrm{CI}=0.46-0.96 ; \mathrm{p}=0.027)]$ in patients with paroxysmal or persistent AF or atrial flutter adequately treated by standard therapy, including antithrombotics (fig. 1) [46]. Patients with $\mathrm{CHADS}_{2}$ scores $\geq 2$ experienced a greater effect of dronedarone than patients with a CHADS 2 score $\leq 1$ ( $p=0.03$ for interaction). The incidence of hemorrhagic stroke was the same for both dronedarone and placebo $(0.2 \%, \mathrm{p}=0.987)$. The effect of dronedarone on stroke was similar regard- 
less of whether patients were receiving $\mathrm{OAC}$ at baseline $(\mathrm{HR}=0.74 ; 95 \% \mathrm{CI}=0.51-1.09 ; \mathrm{p}=0.124)$.

The incidences of major bleeding ( 1.0 vs. $0.9 \%, \mathrm{p}=$ 0.527 ) and any bleeding ( 6.3 vs. $6.4 \%, \mathrm{p}=0.972)$ in ATHENA were similar in both treatment groups [46]. Moreover, the percentages of patients within the INR therapeutic range were similar for patients in both the dronedarone and placebo groups ( $~ 50 \%$ in either group) throughout the study. These findings suggest that dronedarone has minimal interaction with OACs and that together with novel predictable anticoagulants it may reduce the stroke rates to levels that are closer or comparable to patients without AF [47]

ATHENA is the first study of an antiarrhythmic drug to show a benefit in the reduction of stroke events. The authors of the post hoc analysis suggested several potential mechanisms behind this benefit [46]. In patients with $\mathrm{AF}$, loss of contractility of the left atrial appendage is highly likely to be pathophysiologically linked to stroke. Improving contractility through restoration of the sinus rhythm may reduce the likelihood of emboli forming in the atrial appendage. However, the authors noted that this effect has not been found in previous trials of antiarrhythmic drugs. Dronedarone was associated with modest reductions in blood pressure and slowing of heart rate and reduced risk for acute coronary syndrome; reduction of blood pressure has been shown to decrease the risk of stroke. Moreover, the lack of interaction between dronedarone and OACs may have allowed for more stable INR in the ATHENA population. Other antiarrhythmic drugs, notably amiodarone, interact strongly with warfarin and thereby potentially affect INR stability [48]. While stroke was not a predefined end point of ATHENA, these findings are compelling and worthy of further study in randomized clinical trials. It is important to note that dronedarone is contraindicated in patients with $\mathrm{New}$ York Heart Association class IV heart failure or New York Heart Association class II-III heart failure with a recent decompensation requiring hospitalization or referral to a specialized heart failure clinic [49]. In draft guidance, the UK NICE recommends dronedarone as a second-line treatment of nonpermanent $\mathrm{AF}$ in patients with additional cardiovascular risk factors [50].

\section{OAC Therapies}

The efficacy of warfarin in reducing the risk of stroke in patients with AF has been confirmed by randomized, placebo-controlled clinical trials [51]. A meta-analysis of 6 major studies (Copenhagen Atrial Fibrillation, Aspirin and Anticoagulation; Stroke Prevention in Atrial Fibril- lation; Boston Area Anticoagulation Trial for Atrial Fibrillation; Stroke Prevention in Nonrheumatic Atrial Fibrillation; Canadian Atrial Fibrillation Anticoagulant study; and European Atrial Fibrillation Trial) revealed a $64 \%$ reduction in the risk of stroke in patients with nonrheumatic AF treated with warfarin compared with placebo [52].

A secondary analysis of the Atrial Fibrillation Investigators database of 12 published clinical trials showed that patient age has no impact on the relative benefits of OACs compared with placebo or antiplatelet therapy [53]. However, since older patients are at higher risk of ischemic stroke, the 'absolute benefit' of OAC is likely to increase with patient age.

Andersen and Olsen [54] demonstrated that anticoagulant therapy reduces poststroke mortality in patients with AF and ischemic stroke. In their study $(n=3,670)$, survival was almost doubled in the patients who received anticoagulation treatment compared with those who received no treatment $(\mathrm{HR}=1.91 ; 95 \% \mathrm{CI}=1.44-2.52)$. In a meta-analysis of 29 randomized trials of antithrombotic agents in patients $(n=28,044)$ with nonvalvular AF, Hart et al. [55] found that warfarin reduced the risk of ischemic stroke by $64 \%$ (95\% CI $=49-74 \%)$.

The REACH (Reduction of Atherothrombosis for Continued Health) registry confirmed the relationship between $\mathrm{CHADS}_{2}$ score and stroke risk in a worldwide population of patients with AF [56]. However, anticoagulant use ranged from $44.7 \%$ of the patients with $\mathrm{CHADS}_{2}$ score 0 to $60.0 \%$ of the patients with $\mathrm{CHADS}_{2}$ score 4 . In clinical practice it appears that OAC treatment is not tailored to stroke risk [57, 58], although adherence to the guidelines reduces the risk of stroke [59]. The risk of hemorrhage and need for frequent monitoring of prothrombin time or INR with conventional adjusted-dose warfarin has led to the investigation of alternative treatment options.

\section{Other Antithrombotic Therapies}

The therapeutic alternatives to warfarin include antiplatelet agents such as aspirin and clopidogrel. However, aspirin is far less effective than adjusted-dose warfarin in reducing the risk of stroke in patients with AF (approximately 22 vs. $60 \%$ reduction) [55].

In the Stroke Prevention in Atrial Fibrillation III trial, the efficacy of a combination of low-intensity, fixed-dose warfarin with aspirin was compared with adjusted-dose warfarin [60]. After a mean follow-up of 1.1 years, the rate of ischemic stroke and systemic embolism with the combination therapy was significantly higher compared with adjusted-dose warfarin $(\mathrm{p}<0.0001)$, and the trial was dis- 
continued. The secondary analysis of the Atrial Fibrillation Investigators database of 12 clinical trials found that, compared with placebo, both OACs and antiplatelet agents significantly reduced the risk of ischemic stroke in patients with nonvalvular AF (OACs: $\mathrm{HR}=0.36$; $95 \%$ $\mathrm{CI}=0.29-0.45$; antiplatelets: $\mathrm{HR}=0.81 ; 95 \% \mathrm{CI}=0.72$ 0.90) [53]. However, the researchers also found that the benefit of antiplatelet therapy decreased significantly with age $(\mathrm{p}<0.01)$ while the benefit of OACs did not vary.

The combined use of antiplatelet agents for the prevention of vascular events, including stroke, has been investigated in the ACTIVE W (Atrial Fibrillation Clopidogrel Trial with Irbesartan for Prevention of Vascular Events) trial [61]. In ACTIVE W, warfarin was superior to clopidogrel plus aspirin for the prevention of vascular events in $\mathrm{AF}$ patients at high risk of stroke [relative risk $(\mathrm{RR})=1.44$; $95 \% \mathrm{CI}=1.18-1.76 ; \mathrm{p}=0.0003]$. The recently reported ACTIVE A trial evaluated clopidogrel added to aspirin in comparison with placebo plus aspirin in patients with $\mathrm{AF}$ who had an increased stroke risk but for whom warfarin was unsuitable [62]. The results of the study demonstrated that clopidogrel in addition to aspirin reduced the risk for stroke from 3.3 to $2.4 \%$ per year $(\mathrm{RR}=0.72 ; 95 \% \mathrm{CI}=$ $0.62-0.83 ; \mathrm{p}<0.001)$, with an increase in risk for major bleeding not related to stroke from 1.3 to $2.0 \%(\mathrm{RR}=1.57$; $95 \% \mathrm{CI}=1.29-1.92 ; \mathrm{p}<0.001$ ).

In 2 randomized clinical trials $(n=7,329)$ the oral direct thrombin inhibitor ximelagatran was compared with warfarin and found to be as effective in preventing stroke and systemic embolism in patients with AF [63]. In the SPORTIF III (Stroke Prevention using an ORal Thrombin Inhibitor in atrial Fibrillation) study, acute MI occurred at a statistically nonsignificantly higher rate among patients receiving ximelagatran than in those receiving warfarin (1.1 vs. $0.6 \%$, respectively) [64]. However, in SPORTIF V, the opposite result was found (1.0 vs. 1.4\%) [65]. An analysis of both study databases combined revealed that a total of 50 patients in either treatment group experienced an acute MI. Of those, 8 ximelagatran patients and 13 warfarin patients died [63]. There was no difference in major bleeding rates between the 2 treatments. However, ximelagatran was subsequently withdrawn because of abnormal liver function tests.

RE-LY (Randomized Evaluation of Long-Term Anticoagulant Therapy), the largest AF stroke prevention trial undertaken to date, evaluated 2 doses of the active direct thrombin inhibitor dabigatran (110 and $150 \mathrm{mg}$ b.i.d.) in 18,113 patients with nonvalvular $\mathrm{AF}$ [66]. At a low dose (110 $\mathrm{mg}$ b.i.d.) dabigatran was as effective as adjusteddose warfarin in reducing the primary outcome of stroke or systemic embolism, and at a high dose (150 mg b.i.d.) it was superior to warfarin. The primary outcome occurred at rates of $1.69 \%$ per year in patients receiving warfarin and 1.53 and $1.11 \%$ per year in patients receiving dabigatran 110 and $150 \mathrm{mg}$, respectively. The RRs compared with warfarin were 0.91 for $110 \mathrm{mg}(95 \% \mathrm{CI}=0.74-$ 1.11; $\mathrm{p}<0.001$ for noninferiority) and 0.66 for $150 \mathrm{mg}$ (95\% CI $=0.53-0.82 ; \mathrm{p}<0.001$ for superiority). The rates of major bleeding were significantly lower for dabigatran $110 \mathrm{mg}$ than warfarin ( 2.71 vs. $3.36 \%$ per year, $\mathrm{p}=0.003$ ) but similar to warfarin for the higher dose of dabigatran $(3.11 \%, p=0.31)$. Intracranial bleeding was significantly lower for both doses of dabigatran than for warfarin $(\mathrm{p}<$ 0.001 for each dose vs. warfarin). Gastrointestinal bleeding was significantly higher for dabigatran $150 \mathrm{mg}$ than for warfarin $(p<0.001)$ but comparable between dabigatran $110 \mathrm{mg}$ and warfarin. The rates of MI were higher for either dose of dabigatran than for warfarin $(\mathrm{RR}=1.35$; $95 \% \mathrm{CI}=0.98-1.87, \mathrm{p}=0.07$, and $\mathrm{RR}=1.38 ; 95 \% \mathrm{CI}=$ $1.00-1.91, \mathrm{p}=0.048$, for dabigatran 110 and $150 \mathrm{mg}$, respectively). The difference in risk for MI led the researchers to speculate that warfarin may provide better protection against coronary ischemia than dabigatran.

The option to have 2 different doses with either higher efficacy or a lower bleeding rate is appealing and raises the question of which patient might qualify for the one or the other. One might discuss that patients with lower $\mathrm{CHADS}_{2}$ scores (1,2 and possibly 3) qualify for the low dose and patients with $\mathrm{CHADS}_{2} \geq 3$ for the high dosage. While this concept may be intriguing, it is important to consider that a high cardioembolic risk means that the bleeding risk is higher as well. These questions therefore need to be answered by future trials.

\section{Cost of Managing Stroke}

The stroke-related costs vary greatly depending on region and stroke severity. In a meta-analysis of 120 cost surveys from 15 countries (predominantly USA, UK and Sweden), Luengo-Fernandez et al. [67] found a range of USD 468 to 146,149, with a mean cost of USD 19,018 (median $=$ USD 14,571) per event. In the USA, the annual costs of AF-associated stroke are estimated at USD 12 billion (2006) [68].

Nevertheless, the costs of caring for patients with stroke associated with AF have been demonstrated to be significantly higher than for those whose stroke was not associated with AF. In the Berlin Acute Stroke study, the mean direct costs per patient were approximately 33\% greater for AF-related stroke (EUR 11,799) than for nonAF stroke (EUR 8,817) [69]. 


\section{Conclusions}

Patients with AF have a high risk of stroke and are also at an increased risk of stroke recurrence. Warfarin is currently the standard of care for high-risk AF patients and in patients with AF who have had a stroke or TIA. However, warfarin therapy requires regular monitoring and poses an increased risk for hemorrhagic complications. Also, despite clear recommendations in treatment guidelines, warfarin is underutilized by at-risk patients. Novel antithrombotic agents and antiarrhythmic agents offer new opportunities for the management of stroke risk in patients with AF.

\section{Acknowledgements}

Editorial support for this review was provided by Mark Poirier and funded by Sanofi-Aventis.

\section{Disclosures}

J.R. is a consultant to and has served on advisory boards for Sanofi-Aventis, Boehringer Ingelheim, Lundbeck and Bayer. H.C. is a consultant to and has served on advisory boards for Sanofi-Aventis, Astra-Zeneca and Medacorp.

\section{References}

1 Fuster V, Ryden LE, Cannom DS, Crijns HJ, Curtis AB, Ellenbogen KA, Halperin JL, Le Heuzey JY, Kay GN, Lowe JE, Olsson SB, Prystowsky EN, Tamargo JL, Wann S: ACC/ AHA/ESC 2006 guidelines for the management of patients with atrial fibrillation-executive summary: a report of the American College of Cardiology/American Heart Association Task Force on Practice Guidelines and the European Society of Cardiology Committee for Practice Guidelines (Writing Committee to Revise the 2001 Guidelines for the Management of Patients with Atrial Fibrillation). Eur Heart J 2006;27:1979-2030.

$\checkmark 2$ Go AS, Hylek EM, Phillips KA, Chang Y, Henault LE, Selby JV, Singer DE: Prevalence of diagnosed atrial fibrillation in adults: national implications for rhythm management and stroke prevention: the AnTicoagulation and Risk Factors in Atrial Fibrillation (ATRIA) Study. JAMA 2001;285:2370-2375.

-3 Krahn AD, Manfreda J, Tate RB, Mathewson FA, Cuddy TE: The natural history of atrial fibrillation: incidence, risk factors, and prognosis in the Manitoba Follow-Up Study. Am J Med 1995;98:476-484.

-4 Miyasaka Y, Barnes ME, Bailey KR, Cha SS, Gersh BJ, Seward JB, Tsang TS: Mortality trends in patients diagnosed with first atrial fibrillation: a 21-year community-based study. J Am Coll Cardiol 2007;49:986-992.

-5 Stewart S, Hart CL, Hole DJ, McMurray JJ: A population-based study of the long-term risks associated with atrial fibrillation: $20-$ year follow-up of the Renfrew/Paisley study. Am J Med 2002;113:359-364.

6 Wolf PA, Abbott RD, Kannel WB: Atrial fibrillation as an independent risk factor for stroke: the Framingham Study. Stroke 1991; 22:983-988.

$>_{8}$
$>_{9}$
$>_{11}$

Wang TJ, Massaro JM, Levy D, Vasan RS, Wolf PA, D’Agostino RB, Larson MG, Kannel WB, Benjamin EJ: A risk score for predicting stroke or death in individuals with new-onset atrial fibrillation in the community: the Framingham Heart Study. JAMA 2003;290:1049-1056.

8 Boysen G, Nyboe J, Appleyard M, Sorensen PS, Boas J, Somnier F, Jensen G, Schnohr P: Stroke incidence and risk factors for stroke in Copenhagen, Denmark. Stroke 1988;19: 1345-1353.

9 Friberg J, Scharling H, Gadsboll N, Truelsen $\mathrm{T}$, Jensen GB: Comparison of the impact of atrial fibrillation on the risk of stroke and cardiovascular death in women versus men (The Copenhagen City Heart Study). Am J Cardiol 2004;94:889-894.

10 Sacco RL, Boden-Albala B, Abel G, Lin IF, Elkind M, Hauser WA, Paik MC, Shea S: Race-ethnic disparities in the impact of stroke risk factors: the northern Manhattan stroke study. Stroke 2001;32:1725-1731.

11 Nieuwlaat R, Dinh T, Olsson SB, Camm AJ, Capucci A, Tieleman RG, Lip GY, Crijns HJ: Should we abandon the common practice of withholding oral anticoagulation in paroxysmal atrial fibrillation? Eur Heart J 2008;29: 915-922.

12 Capucci A, Santini M, Padeletti L, Gulizia M, Botto G, Boriani G, Ricci R, Favale S, Zolezzi F, Di Belardino N, Molon G, Drago F, Villani GQ, Mazzini E, Vimercati M, Grammatico A: Monitored atrial fibrillation duration predicts arterial embolic events in patients suffering from bradycardia and atrial fibrillation implanted with antitachycardia pacemakers. J Am Coll Cardiol 2005;46: 1913-1920.

-13 Lin HJ, Wolf PA, Kelly-Hayes M, Beiser AS, Kase CS, Benjamin EJ, D'Agostino RB: Stroke severity in atrial fibrillation: The Framingham Study. Stroke 1996;27:17601764.
14 Lavy S, Stern S, Melamed E, Cooper G, Keren A, Levy P: Effect of chronic atrial fibrillation on regional cerebral blood flow. Stroke 1980; 11:35-38.

-15 Marini C, De Santis F, Sacco S, Russo T, Olivieri $L$, Totaro $R$, Carolei A: Contribution of atrial fibrillation to incidence and outcome of ischemic stroke: results from a population-based study. Stroke 2005;36:1115-1119.

16 Dhamoon MS, Tai W, Boden-Albala B, Rundek T, Paik MC, Sacco RL, Elkind MS: Risk of myocardial infarction or vascular death after first ischemic stroke: the Northern Manhattan Study. Stroke 2007;38:17521758 .

17 Dhamoon MS, Sciacca RR, Rundek T, Sacco RL, Elkind MS: Recurrent stroke and cardiac risks after first ischemic stroke: the Northern Manhattan Study. Neurology 2006;66: 641-646.

18 Kirchhof P, Bax J, Blomstrom-Lundquist C, Calkins H, John CA, Cappato R, Cosio F, Crijns H, Diener HC, Goette A, Israel CW, Kuck KH, Lip GY, Nattel S, Page RL, Ravens U, Schotten U, Steinbeck G, Vardas P, Waldo A, Wegscheider K, Willems S, Breithardt G: Early and comprehensive management of atrial fibrillation: executive summary of the proceedings from the 2nd AFNET-EHRA consensus conference research perspectives in AF. Eur Heart J 2009;30:2969-2977.

19 Jabaudon D, Sztajzel J, Sievert K, Landis T, Sztajzel R: Usefulness of ambulatory 7-day ECG monitoring for the detection of atrial fibrillation and flutter after acute stroke and transient ischemic attack. Stroke 2004;35: 1647-1651.

20 Tayal AH, Tian M, Kelly KM, Jones SC, Wright DG, Singh D, Jarouse J, Brillman J, Murali S, Gupta R: Atrial fibrillation detected by mobile cardiac outpatient telemetry in cryptogenic TIA or stroke. Neurology 2008; 71:1696-1701. 
-21 Israel CW, Gronefeld G, Ehrlich JR, Li YG, Hohnloser SH: Long-term risk of recurrent atrial fibrillation as documented by an implantable monitoring device: implications for optimal patient care. J Am Coll Cardiol 2004;43:47-52.

22 Savelieva I, Camm AJ: Clinical relevance of silent atrial fibrillation: prevalence, prognosis, quality of life, and management. J Interv Card Electrophysiol 2000;4:369-382.

-23 Hart RG, Benavente O, McBride R, Pearce LA: Antithrombotic therapy to prevent stroke in patients with atrial fibrillation: a meta-analysis. Ann Intern Med 1999;131: 492-501.

-24 European Stroke Organisation (ESO) Executive Committee, ESO Writing Committee: Guidelines for management of ischaemic stroke and transient ischaemic attack 2008. Cerebrovasc Dis 2008;25:457-507.

25 Gage BF, Waterman AD, Shannon W, Boechler M, Rich MW, Radford MJ: Validation of clinical classification schemes for predicting stroke: results from the National Registry of Atrial Fibrillation. JAMA 2001; 285:2864-2870.

26 Goldstein LB, Adams R, Alberts MJ, Appel LJ, Brass LM, Bushnell CD, Culebras A, Degraba TJ, Gorelick PB, Guyton JR, Hart RG, Howard G, Kelly-Hayes M, Nixon JV, Sacco RL: Primary prevention of ischemic stroke: a guideline from the American Heart Association/American Stroke Association Stroke Council: cosponsored by the Atherosclerotic Peripheral Vascular Disease Interdisciplinary Working Group; Cardiovascular Nursing Council; Clinical Cardiology Council; Nutrition, Physical Activity, and Metabolism Council; and the Quality of Care and Outcomes Research Interdisciplinary Working Group: the American Academy of Neurology affirms the value of this guideline. Stroke 2006;37:1583-1633.

-27 Sacco RL, Adams R, Albers G, Alberts MJ, Benavente O, Furie K, Goldstein LB, Gorelick P, Halperin J, Harbaugh R, Johnston SC, Katzan I, Kelly-Hayes M, Kenton EJ, Marks M, Schwamm LH, Tomsick T: Guidelines for prevention of stroke in patients with ischemic stroke or transient ischemic attack: a statement for healthcare professionals from the American Heart Association/American Stroke Association Council on Stroke: cosponsored by the Council on Cardiovascular Radiology and Intervention: the American Academy of Neurology affirms the value of this guideline. Stroke 2006;37:577-617.

28 National Institute for Health and Clinical Excellence: Stroke: diagnosis and initial management of acute stroke and transient ischemic attack (TIA). NICE Clinical Guideline 68. National Guideline Clearinghouse Website. http:/guideline.gov/summary/ summary.aspx?ss $=15 \&$ doc_id $=14328 \&$ string $=($ accessed April 20, 2010 $)$.
29 Paciaroni M, Agnelli G, Micheli S, Caso V: Efficacy and safety of anticoagulant treatment in acute cardioembolic stroke: a metaanalysis of randomized controlled trials. Stroke 2007;38:423-430.

30 Adams HP Jr: Emergent use of anticoagulation for treatment of patients with ischemic stroke. Stroke 2002;33:856-861.

31 Hylek EM, Go AS, Chang Y, Jensvold NG, Henault LE, Selby JV, Singer DE: Effect of intensity of oral anticoagulation on stroke severity and mortality in atrial fibrillation. $\mathrm{N}$ Engl J Med 2003;349:1019-1026.

32 O’Donnell M, Oczkowski W, Fang J, Kearon C, Silva J, Bradley C, Guyatt G, Gould L, D’Uva C, Kapral M, Silver F: Preadmission antithrombotic treatment and stroke severity in patients with atrial fibrillation and acute ischaemic stroke: an observational study. Lancet Neurol 2006;5:749-754.

33 Mant J, Hobbs FD, Fletcher K, Roalfe A, Fitzmaurice D, Lip GY, Murray E: Warfarin versus aspirin for stroke prevention in an elderly community population with atrial fibrillation (the Birmingham Atrial Fibrillation Treatment of the Aged Study, BAFTA): a randomised controlled trial. Lancet 2007; 370:493-503.

34 Rash A, Downes T, Portner R, Yeo WW, Morgan N, Channer KS: A randomised controlled trial of warfarin versus aspirin for stroke prevention in octogenarians with atrial fibrillation (WASPO). Age Ageing 2007; 36:151-156.

35 Hughes M, Lip GY: Risk factors for anticoagulation-related bleeding complications in patients with atrial fibrillation: a systematic review. QJM 2007;100:599-607.

-36 Gage BF, Yan Y, Milligan PE, Waterman AD, Culverhouse R, Rich MW, Radford MJ: Clinical classification schemes for predicting hemorrhage: results from the National Registry of Atrial Fibrillation (NRAF). Am Heart J 2006;151:713-719.

37 Roy D, Talajic M, Nattel S, Wyse DG, Dorian P, Lee KL, Bourassa MG, Arnold JM, Buxton AE, Camm AJ, Connolly SJ, Dubuc $\mathrm{M}$, Ducharme A, Guerra PG, Hohnloser SH, Lambert J, Le Heuzey JY, O’Hara G, Pedersen OD, Rouleau JL, Singh BN, Stevenson LW, Stevenson WG, Thibault B, Waldo AL: Rhythm control versus rate control for atrial fibrillation and heart failure. N Engl J Med 2008;358:2667-2677.

38 Wyse DG, Waldo AL, DiMarco JP, Domanski MJ, Rosenberg Y, Schron EB, Kellen JC, Greene HL, Mickel MC, Dalquist JE, Corley SD: A comparison of rate control and rhythm control in patients with atrial fibrillation. N Engl J Med 2002;347:1825-1833.

39 Opolski G, Torbicki A, Kosior DA, Szulc M, Wozakowska-Kaplon B, Kolodziej P, Achremczyk P: Rate control vs rhythm control in patients with nonvalvular persistent atrial fibrillation: the results of the Polish How to Treat Chronic Atrial Fibrillation (HOT CAFE) Study. Chest 2004;126:476-486.
40 Van Gelder IC, Hagens VE, Bosker HA, Kingma JH, Kamp O, Kingma T, Said SA, Darmanata JI, Timmermans AJ, Tijssen JG, Crijns HJ: A comparison of rate control and rhythm control in patients with recurrent persistent atrial fibrillation. N Engl J Med 2002;347:1834-1840.

41 Carlsson J, Miketic S, Windeler J, Cuneo A, Haun S, Micus S, Walter S, Tebbe U: Randomized trial of rate-control versus rhythmcontrol in persistent atrial fibrillation: the Strategies of Treatment of Atrial Fibrillation (STAF) study. J Am Coll Cardiol 2003;41: 1690-1696.

42 Sherman DG: Stroke prevention in atrial fibrillation: pharmacological rate versus rhythm control. Stroke 2007;38(suppl 2): 615-617.

43 Camm AJ, Reiffel JA: Defining endpoints in clinical trials on atrial fibrillation. Eur Heart J Suppl 2008;10(suppl H):H55-H78.

44 Singh BN, Singh SN, Reda DJ, Tang XC, Lopez B, Harris CL, Fletcher RD, Sharma SC, Atwood JE, Jacobson AK, Lewis HD Jr, Raisch DW, Ezekowitz MD: Amiodarone versus sotalol for atrial fibrillation. $\mathrm{N}$ Engl J Med 2005;352:1861-1872.

45 Hohnloser SH, Crijns HJ, van Eickels M, Gaudin C, Page RL, Torp-Pedersen C, Connolly SJ: Effect of dronedarone on cardiovascular events in atrial fibrillation. N Engl J Med 2009;360:668-678

$\checkmark 46$ Connolly SJ, Crijns HJ, Torp-Pedersen C, van Eickels M, Gaudin C, Page RL, Hohnloser SH: Analysis of stroke in ATHENA: a placebo-controlled, double-blind, parallelarm trial to assess the efficacy of dronedarone $400 \mathrm{mg}$ BID for the prevention of cardiovascular hospitalization or death from any cause in patients with atrial fibrillation/atrial flutter. Circulation 2009;120:1174-1180.

47 Ezekowitz MD, Koti MJ, Fulton B: Reducing stroke rates in patients with atrial fibrillation: how low can we go? Circulation 2009; 120:1169-1170.

48 Trujillo TC, Nolan PE: Antiarrhythmic agents: drug interactions of clinical significance. Drug Saf 2000;23:509-532.

49 Multaq Prescribing Information. Bridgewater, Sanofi-Aventis US LLC, 2009.

50 National Institute for Health and Clinical Excellence: Atrial fibrillation - dronedarone: appraisal consultation document 2 . NICE Website. http://www.nice.org.uk/ guidance/index.jsp?action $=$ article $\& o=$ 48099 (accessed April 20, 2010).

51 Risk factors for stroke and efficacy of antithrombotic therapy in atrial fibrillation: analysis of pooled data from five randomized controlled trials. Arch Intern Med 1994; 154:1449-1457.

52 Morley J, Marinchak R, Rials SJ, Kowey P: Atrial fibrillation, anticoagulation, and stroke. Am J Cardiol 1996;77:38A-44A. 
-53 Van Walraven C, Hart RG, Connolly S, Austin PC, Mant J, Hobbs FD, Koudstaal PJ, Petersen P, Perez-Gomez F, Knottnerus JA, Boode B, Ezekowitz MD, Singer DE: Effect of age on stroke prevention therapy in patients with atrial fibrillation: the atrial fibrillation investigators. Stroke 2009;40:1410-1416.

54 Andersen KK, Olsen TS: Reduced poststroke mortality in patients with stroke and atrial fibrillation treated with anticoagulants: results from a Danish quality-control registry of 22,170 patients with ischemic stroke. Stroke 2007;38:259-263.

55 Hart RG, Pearce LA, Aguilar MI: Meta-analysis: antithrombotic therapy to prevent stroke in patients who have nonvalvular atrial fibrillation. Ann Intern Med 2007;146: 857-867.

56 Goto S, Bhatt DL, Rother J, Alberts M, Hill MD, Ikeda Y, Uchiyama S, D'Agostino R, Ohman EM, Liau CS, Hirsch AT, Mas JL, Wilson PW, Corbalan R, Aichner F, Steg PG: Prevalence, clinical profile, and cardiovascular outcomes of atrial fibrillation patients with atherothrombosis. Am Heart J 2008; 156:855-863.

57 Waldo AL, Becker RC, Tapson VF, Colgan KJ: Hospitalized patients with atrial fibrillation and a high risk of stroke are not being provided with adequate anticoagulation. J Am Coll Cardiol 2005;46:1729-1736.

-58 Nieuwlaat R, Capucci A, Lip GY, Olsson SB, Prins $\mathrm{MH}$, Nieman FH, Lopez-Sendon J, Vardas PE, Aliot E, Santini M, Crijns HJ: Antithrombotic treatment in real-life atrial fibrillation patients: a report from the Euro Heart Survey on Atrial Fibrillation. Eur Heart J 2006;27:3018-3026.
59 Nieuwlaat R, Olsson SB, Lip GY, Camm AJ, Breithardt G, Capucci A, Meeder JG, Prins MH, Levy S, Crijns HJ: Guideline-adherent antithrombotic treatment is associated with improved outcomes compared with undertreatment in high-risk patients with atrial fibrillation: The Euro Heart Survey on Atrial Fibrillation. Am Heart J 2007;153:10061012.

60 Adjusted-dose warfarin versus low-intensity, fixed-dose warfarin plus aspirin for highrisk patients with atrial fibrillation: Stroke Prevention in Atrial Fibrillation III randomised clinical trial. Lancet 1996;348:633638.

61 Connolly S, Pogue J, Hart R, Pfeffer M Hohnloser S, Chrolavicius S, Yusuf S: Clopidogrel plus aspirin versus oral anticoagulation for atrial fibrillation in the Atrial fibrillation Clopidogrel Trial with Irbesartan for prevention of Vascular Events (ACTIVE W): a randomised controlled trial. Lancet 2006; 367:1903-1912.

62 Connolly S, Pogue J, Hart R, Pfeffer M Hohnloser S, Chrolavicius S, Yusuf S: Effect of Clopidogrel Added to Aspirin in Patients with Atrial Fibrillation. N Engl J Med 2009; 360:2066-2078.

63 Diener HC: Stroke prevention using the oral direct thrombin inhibitor ximelagatran in patients with non-valvular atrial fibrillation: Pooled analysis from the SPORTIF III and V studies. Cerebrovasc Dis 2006;21:279-293.
64 Olsson SB: Stroke prevention with the oral direct thrombin inhibitor ximelagatran compared with warfarin in patients with non-valvular atrial fibrillation (SPORTIF III): randomised controlled trial. Lancet 2003;362:1691-1698.

65 Albers GW, Diener HC, Frison L, Grind M, Nevinson M, Partridge S, Halperin JL, Horrow J, Olsson SB, Petersen P, Vahanian A: Ximelagatran vs warfarin for stroke prevention in patients with nonvalvular atrial fibrillation: a randomized trial. JAMA 2005; 293:690-698.

-66 Connolly SJ, Ezekowitz MD, Yusuf S, Eikelboom J, Oldgren J, Parekh A, Pogue J, Reilly PA, Themeles E, Varrone J, Wang S, Alings M, Xavier D, Zhu J, Diaz R, Lewis BS, Darius H, Diener HC, Joyner CD, Wallentin L: Dabigatran versus warfarin in patients with atrial fibrillation. N Engl J Med 2009;361:11391151.

67 Luengo-Fernandez R, Gray AM, Rothwell PM: Costs of stroke using patient-level data: a critical review of the literature. Stroke 2009;40:e18-e23.

68 Maddox TM, Nash IS, Fuster V: Economic costs associated with atrial fibrillation; in Natale A, Jalife J (eds): Atrial Fibrillation, Bench to Bedside. Totawa Humana Press, 2008.

-69 Bruggenjurgen B, Rossnagel K, Roll S, Andersson FL, Selim D, Muller-Nordhorn J, Nolte CH, Jungehulsing GJ, Villringer A, Willich SN: The impact of atrial fibrillation on the cost of stroke: the Berlin Acute Stroke study. Value Health 2007;10:137-143. 